GU J Sci, Part C, 6(3): 536-543 (2018)

Gazi Üniversitesi
Fen Bilimleri Dergisi
PART C: TASARIM VE TEKNOLOJI
dergipark.gov.tr/http-gujsc-gazi-edu-tr

\title{
Anahtarlamalı Relüktans Motor Tabanlı Medikal Santrifüj Sistemi
}

\author{
Nurettin ÜSTKOYUNCU ${ }^{1, *}$, Osman EROĞUL

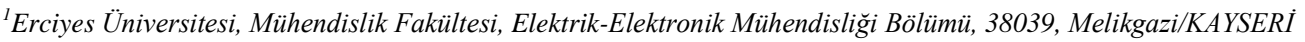

Makale Bilgisi

Başvuru:18/12/2017

Düzeltme: 01/03/2018

Kabul:22/05/2018

Anahtar Kelimeler

Medikal santrifüj sistemi Anahtarlamalı relüktans motor (ARM)

Keywords

Medical centrifuge system Switched reluctance motor $(S R M)$

\begin{abstract}
$\ddot{O} z$
$\mathrm{Bu}$ çalışmada, anahtarlamalı relüktans motor (ARM) tabanlı bir medikal santrifüj sistemi tasarlanmış ve prototip olarak gerçekleştirilmiştir. Medikal santrifüj sistemlerinde genel olarak asenkron motorlar ya da kalıcı mıknatıslı motor yapıları kullanılıyor olmasına karşın, yapılan çalışmada diğer elektrik motorları ile karşılaştırıldığında birçok avantaja sahip olan bir ARM tahrik motoru olarak tasarlanmış ve kullanılmıştır. ARM'nin istenilen şekilde çalışmasını sağlayacak olan sürücü ünitesi ve diğer tüm mekanik aksamlar da çalışma esnasında tasarlanmış ve gerçekleştirilmiştir. Yapılan çalışma, uygun maliyetli medikal santrifüj cihazlarının farklı teknolojik özelliklerle birlikte ortaya konulabileceğini göstermektedir.
\end{abstract}

\section{A Medical Centrifuge System Based on the Switched Reluctance Motor}

\begin{abstract}
A prototype medical centrifuge system based on switched reluctance motors (SRMs) is designed and realized in this study. Although medical centrifuge systems use asynchronous motors or motor structures with permanent magnets in general, an SRM had many advantages compared to other types of electrical motors is designed and used as a drive motor in the study. A driver unit to operate the system under desired conditions and all mechanical components are designed and manufactured in the study. Therefore, the study shows that the cost effective medical centrifuge systems can be produced with different technological specifications.
\end{abstract}

\section{GİRIŞ (INTRODUCTION)}

Medikal santrifüj cihazları, genel olarak bir elektrikli motor yardımıyla sabit eksenli, dairesel dönme hareketi gerçekleştiren ve çok yaygın bir şekilde kullanılan laboratuar cihazlarındandır. Santrifüj işlemi sonrasında sıvı ortam içerisinde yer alan partiküllerin ve yoğunlukları farklı olan iki sıvının birbirinden ayrılması sağlanabilmektedir. Santrifüj cihazlarının sahip olduğu yüksek devir, cihazlara yerleştirilmiş olan karışımların merkezkaç kuvveti yardımıyla çökme prensibine göre ayrılmasını sağlamaktadır [1]. Birçok tahlilin gerçekleştirilmesinde önemli rol oynayan ve hastaneler ile laboratuar merkezleri için vazgeçilmez cihazların başında gelen medikal santrifüj sistemlerinin gereksinim ve uygulama alanlarına bağlı olarak farklı boyutlarda üretilmesi mümkündür.

Anahtarlamalı relüktans motorlar (ARM), diğer elektrik motorlarıyla kıyaslandığında son derece basit bir yapıya sahip olan elektrik motorlarıdır. Özellikle değişken hızlı uygulamalar dikkate alındığında diğer elektrik motorlarına çok ciddi bir alternatif olan ARM'lerin hem statoru hem de rotoru çıkıntılı yapıya sahip olup sadece statorda sarg1 bulunurken rotorda herhangi bir sarg1 ya da kalıc1 mıknatıs bulunmamaktadır. ARM'lerde stator ve rotor arasındaki hava aralığının relüktans değeri, kutupların çıkıntılı yapıya sahip olmasından dolayı değişkendir ve ARM'lerin çalışma prensibi de bu relüktans değişimi ile ilgilidir. ARM'ler diğer elektrik motorları ile kıyaslandığında düşük üretim maliyeti, geniş 
bir hız sahası içerisinde yüksek tork üretebilme kabiliyeti, sağlamlık, kolay üretilebilirlik ve bakıma gereksinim duymama gibi birçok avantaja sahiptir [2-5].

Medikal santrifüj sistemlerinde döner kısım olan santrifüj rotorunun hareketi genel olarak elektrik motorları ile sağlanırken, endüstriyel uygulamalarda genel olarak hidrolik sistemlerle bu işlem gerçekleştirilmektedir [6-9]. Medikal santrifüj sistemleri için en önemli hususlardan birisi, santrifüj cihazına ait rotorun dönüş hızıdır. Düşük hız değerlerinde çalışan santrifüj sistemleri olduğu gibi çok yüksek hız değerlerinde çalışması gereken sistemler de mevcuttur. Dolayısı ile santrifüj sistemlerinin hassas bir şekilde hızının ayarlanabilme ve geniş bir hız sahası içerisinde çalışabilme kabiliyetlerine sahip olması önemlidir. Medikal santrifüj sistemleri için diğer bir önemli husus, sistemin sağlayabildiği bağıl santrifüj kuvvetidir (Relative Centrifugal Force - RCF). Bağıl santrifüj kuvveti, santrifüj sistemine ait tüplerin merkezinden rotor merkezine olan yarıçapa bağlı olarak değişiklik göstermektedir. Dolayısıyla bu kuvvetin maksimum değeri Eşitlik 1 ile verilebilir [10]:

$$
R C F_{\text {maksimum }}=1.118 \times 10^{-5} \times r_{\text {maksimum }} \times\left(n_{r}\right)^{2}
$$

Eşitlik 1'de $r_{\text {maksimum }}$ ve $n_{r}$ değerleri sırasıyla yarıçapın maksimum değerini ve mekanik dönüş hızını ifade etmektedir. Eşitlik 1'den görülebileceği üzere bağıl santrifüj kuvveti, rotor hızına bağlı olup hızın karesi ile orantılı bir şekilde değişmektedir.

Günümüzde Medikal santrifüj sistemlerinde asenkron motorlar çoğunlukta olmak üzere farklı elektrik motorları kullanılmasına karşın, sunulan bu çalışmada birçok medikal uygulama için yeterli sayılabilecek özelliklere ve yüksek hızlarda çalışma kabiliyetine sahip ARM tabanlı bir medikal santrifüj sistemi tasarlanmış ve prototip olarak ortaya konulmuştur. ARM'leri temel alan medikal santrifüj uygulamalarına ticari olarak rastlanmakla birlikte bu uygulamaların bir hayli sinırlı olduğunu söylemek hatalı olmayacaktır [10].

Sunulan çalışmada, 2. Bölüm'de medikal santrifüj sisteminin temel yapısı ve ARM'nin özellikleri verilecektir. Prototipi gerçekleştirilen sistem ile ilgili hususlara 3. Bölüm'de değinilecek ve 4. Bölüm'de ise elde edilen sonuçlar ve yapılan çalışma değerlendirilecektir.

\section{MEDÍKAL SANTRİÜJ SISTEMİ (THE MEDICAL CENTRIFUGE SYSTEM)}

\subsection{Santrifüj Sisteminin Genel Yapısı ve Bileşenleri (General Structure and Components of the Centrifuge System)}

Sunulan çalışmada prototipi gerçekleştirilen medikal santrifüj sisteminin temel bileşenleri elektronik bileşenler haricinde Şekil 1'de üç boyutlu olarak gösterilmiştir.

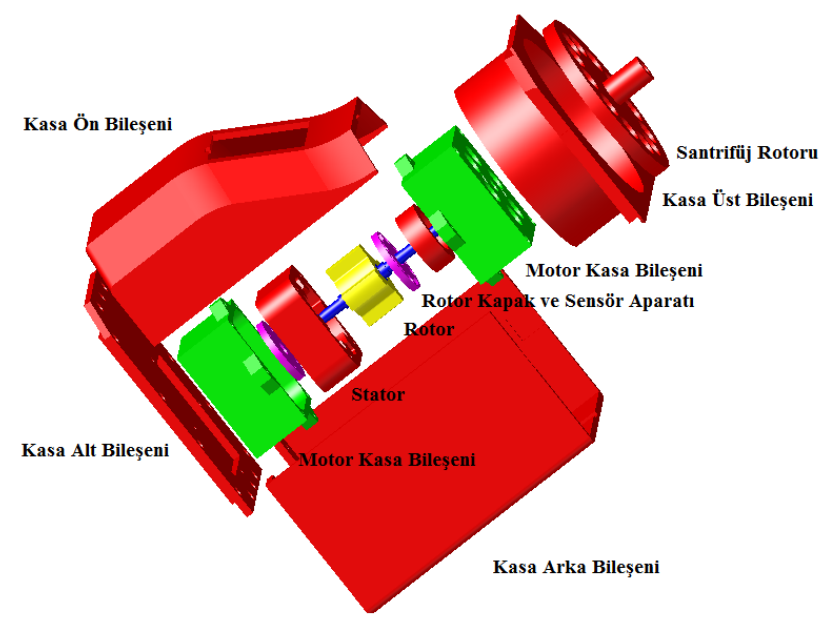

Şekil 1. Santrifüj sisteminin temel bileşenlerinin üç boyutlu görünümü (3D appearance of basic components of the medical centrifuge system) 
Prototip santrifüj sisteminin kasası dört parçadan oluşmakta ve bu parçalardan üst parça haricinde kalanları sistemin diğer bileşenlerinin yerleşimine olanak sağlamaktadır. Kasanın alt parçası üzerine, santrifüj siteminin tahrik motoru olan ARM ve sistemin ana güç kart1, ön parçası üzerine santrifüj sisteminin kontrol edilmesini sağlayan dokunmatik ekran, yan parçası üzerine ise diğer elektronik kartlar yerleştirilmiştir. Sistemin tüm kontrolü ve ayarları dokunmatik ekran üzerinden yapılmakta olup herhangi bir ek buton yer almamaktadır.

Santrifüj sisteminde ARM'nin istenilen şekilde işletilmesini sağlayan bir sürücü ünitesi de tasarlanmış olup sürücü ünitesi, kontrol ve güç kartı olmak üzere iki temel elektronik kart bileşeninden oluşmaktadır. Prototip olarak gerçekleştirilen sistemin temel blok diyagramı Şekil 2'de, sisteme ait elektromekanik ve elektronik bileşenlerin sistemin bir araya getirilmesinden önce test sürecinde alınmış olan görüntüsü ise Şekil 3'te gösterilmiştir.

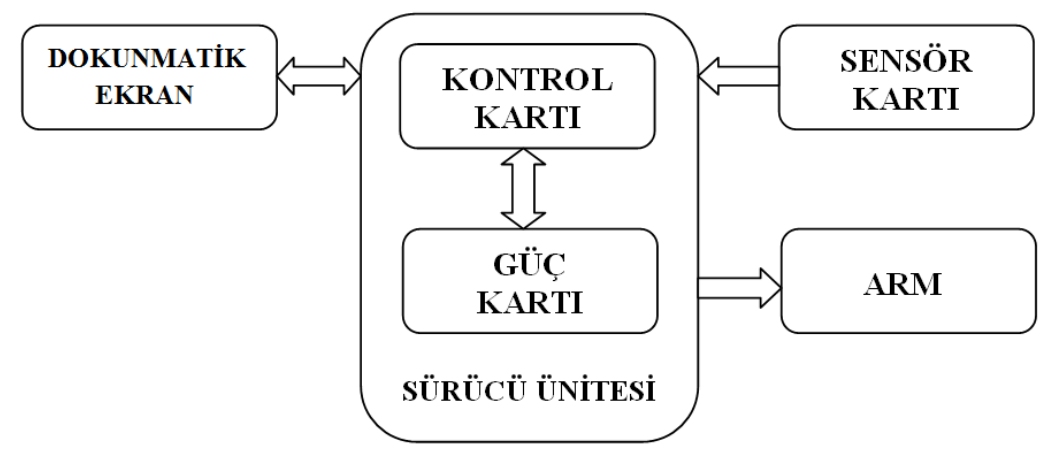

Şekil 2. Sistemin temel blok diyagramı (The basic block diagram of the system)

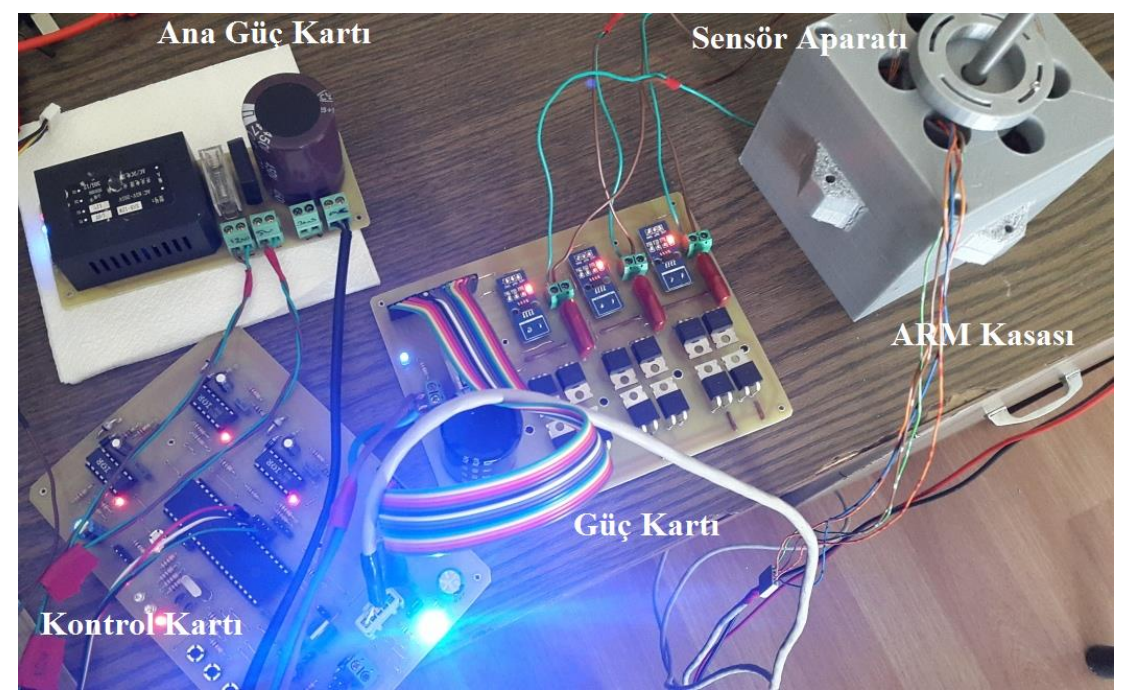

Şekil 3. Santrifüj sisteminin elektromekanik ve elektronik bileşenleri (Electromechanical and electronic components of the centrifuge system)

Çalışmada tasarlanan sürücü ünitesinde kontrol işlemcisi olarak Microchip firması tarafından motor kontrolü için özel olarak tasarlanmış olan DSPIC30F4011 mikrodenetleyicisi kullanılmıştır. Sürücü ünitesi, hem kontrol devresinde yer alan butonlar vasıtasıyla hem de dokunmatik ekran aracılığıla çalışabilir nitelikte tasarlanmıştır. Dolayısıyla dokunmatik ekrana ait kullanıcı ara yüzü geliştirilinceye kadar sistemin test edilmesine olanak sağlanmıştır. 


\subsection{ARM Detayları (Details of the SRM)}

Prototipi gerçekleştirilmiş olan santrifüj sisteminin tahrik motoru olarak kullanılan ARM, üç fazlı olup 6/4 yapısındadır. Stator ve rotor bileşenleri $0.5 \mathrm{~mm}$ kalınlığında silisli saç plakaları kullanılarak oluşturulmuştur. Prototip bir sistem olması ve hızlı sonuçlar alınabilmesi için lazer kesim tekniği ile ilgili saç plakaları stator ve rotor geometrisine göre kesilmiştir. Prototip olarak gerçekleştirilen ARM'nin temel bileşenleri Şekil 4'te gösterilmiştir.

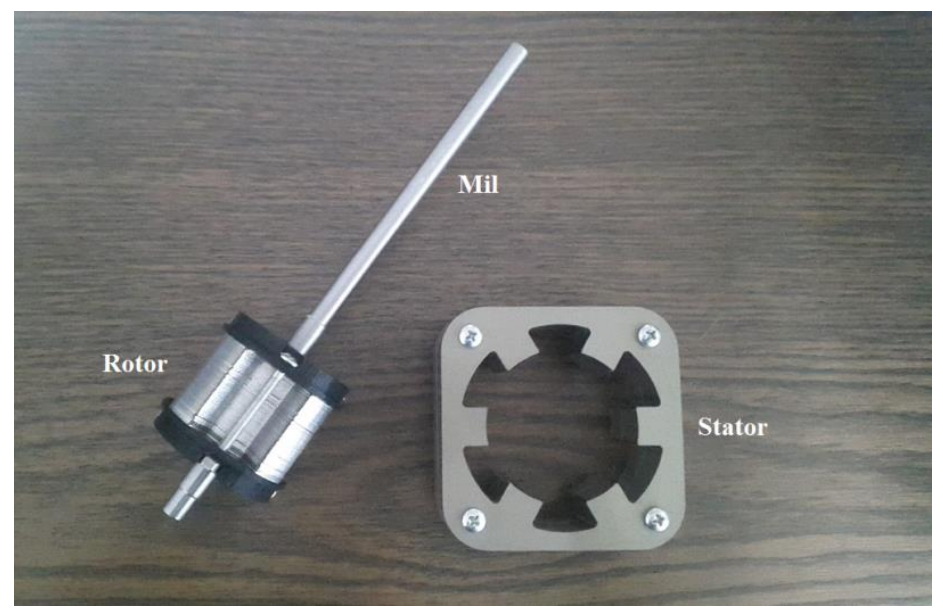

Şekil 4. ARM'ye ait temel bileşenler (Basic components of the SRM)

Çalışmada tasarlanmış olan ARM'nin temel özellikleri Tablo 1'de verilmiş olup benzetim çalışmaları sonuncunda elde edilen motora ait temel bazı performans karakteristikleri Şekil 5' te gösterilmiştir. Aynı zamanda ilgili ARM'nin sonlu elemanlar analizi (SEA) ile ilgili olarak yapılan benzetim çalışmalarından alınmış olan bir görüntü Şekil 6' da gösterilmiştir.

Tablo 1. Prototip ARM'ye ait temel parametreler (Basic Parameters of the prototype SRM)

\begin{tabular}{lr}
\hline Parametreler & Değer \\
\hline Faz Sayısı & 3 \\
Stator Kutup Sayısı & 6 \\
Rotor Kutup Sayısı & 4 \\
Faz Sarım Sayısı (Tur) & 400 \\
Eksenel Uzunluk (mm) & 30 \\
Stator İç Çapı (mm) & 50.5 \\
Hava Aralığı (mm) & 0.25 \\
Stator Kutup Açısı ( $\left.{ }^{\circ}\right)$ & 29 \\
Rotor Kutup Açısı ( ${ }^{\circ}$ & 31 \\
Maksimum Çııış Gücü (W) & 228 \\
Temel Hız (dev/dak) & 5000 \\
Temel Hızdaki Verim (\%) & 70 \\
Anma Hızı (dev/dak) & 10000 \\
Anma Hızındaki Çıkış Gücü (W) & 180 \\
Anma Hızındaki Verim (\%) & 80.2 \\
Maksimum RCF (x g) & 5000 \\
\hline
\end{tabular}




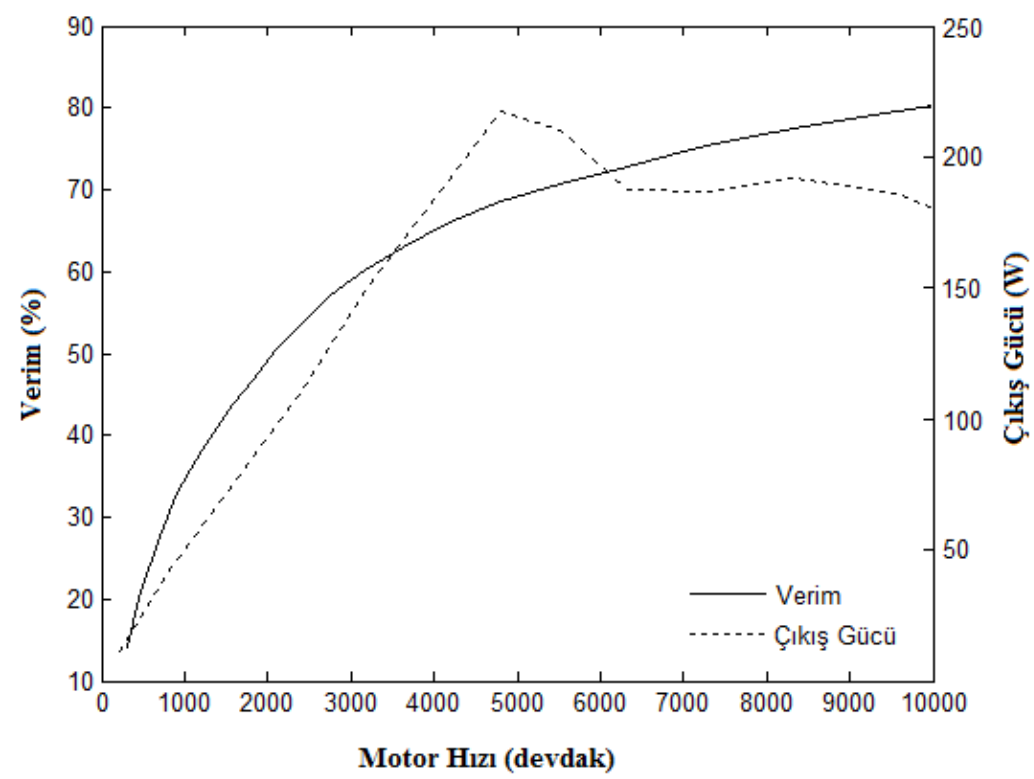

Şekil 5. ARM'ye ait temel performans karakteristikleri (Basic performance characteristics of the SRM)

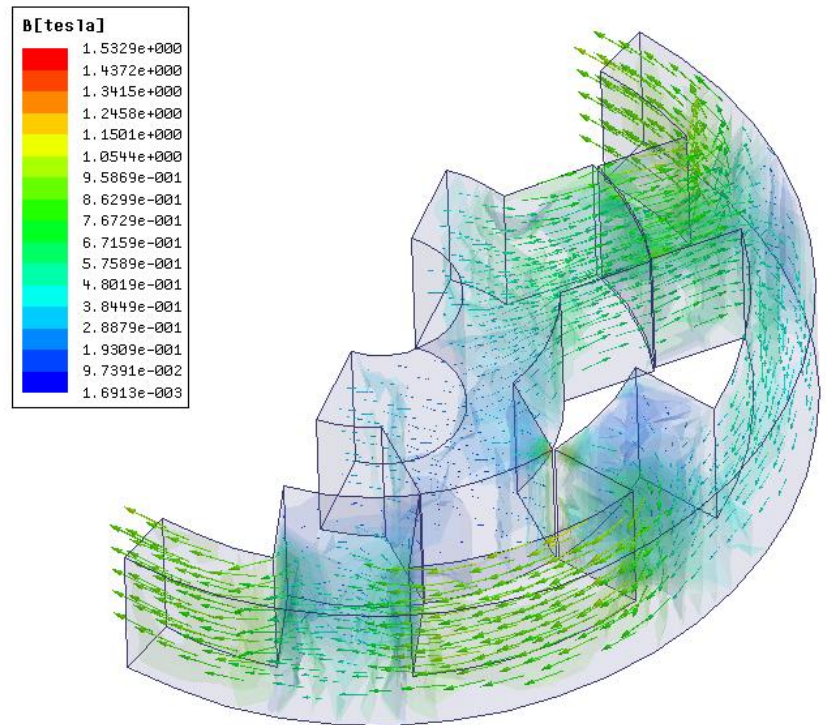

Şekil 6. Çakışık konumda manyetik akı yoğunluğu dağılımının vektörel olarak 3 boyutlu gösterimi (3D vector appearance of the magnetic flux density distribution at the aligned position)

ARM'ye ait akım, halkalanma akısı ve rotor konumu arasındaki ilişkiyi ifade eden temel karakteristiği Şekil 7'de gösterilmiştir. İlgili karakteristik de SEA kullanılarak elde edilmiştir. Çalışmada gerçekleştirilen ARM, geniş bir hız aralığı içerisinde çalışmaya uygun bir şekilde tasarlanmış olup gerek düşük hızlarda gerekse de yüksek hızlarda sağlaması gereken tahrik gücünü cihaza aktarabilmektedir. Cihazın maksimum hızı 10000 dev/dak olarak sinırlandırılmıș ve dolayısıyla ARM'nin maksimum çalışma hızı da bu değer olarak kontrol devresi tarafından denetlenmektedir. 


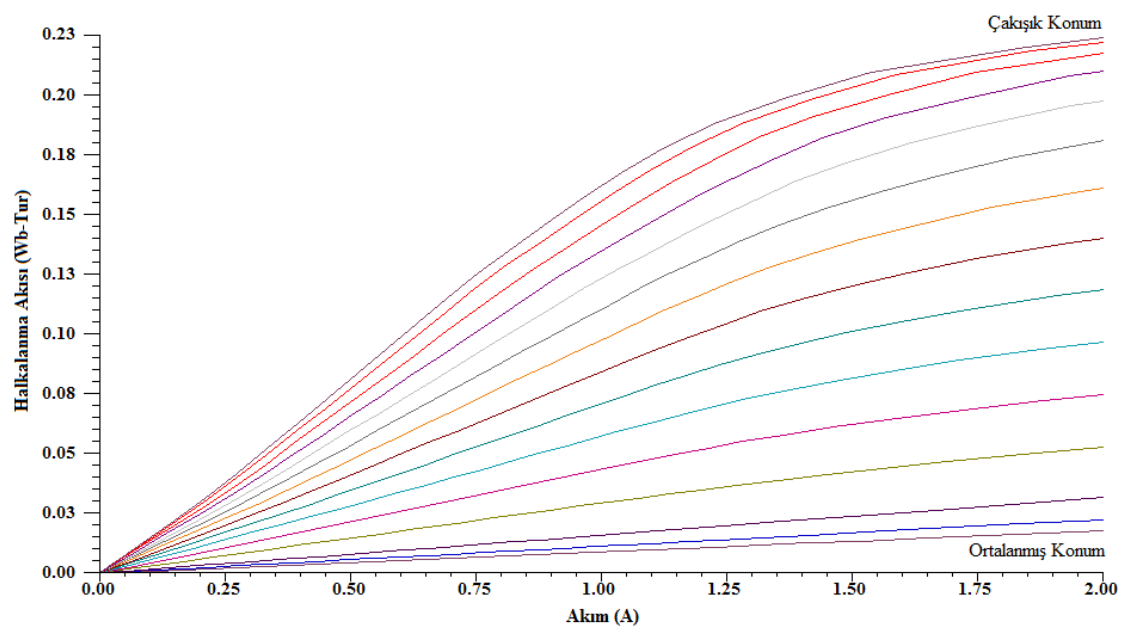

Şekil 7. ARM'ye ait akım-halkalanma akıst-rotor konumu karakteristiği (Current-flux linkage-rotor position characteristics of the SRM)

\section{PROTOTIP SISTEM (THE PROTOTYPE SYSTEM)}

Sunulan çalışmada gerçekleştirilen medikal santrifüj cihazının tüm sistem bileşenlerinin yer aldığı görüntüleri Şekil 8'de gösterilmiştir. Şekil 8'den de görülebileceği üzere santrifüj cihazının kasa bileşenleri, tasarım sürecinin ardından gerek maliyetlerin gerekse de üretim süresinin azaltılabilmesi adına üç boyutlu yazıcı kullanılarak üretilmiştir.

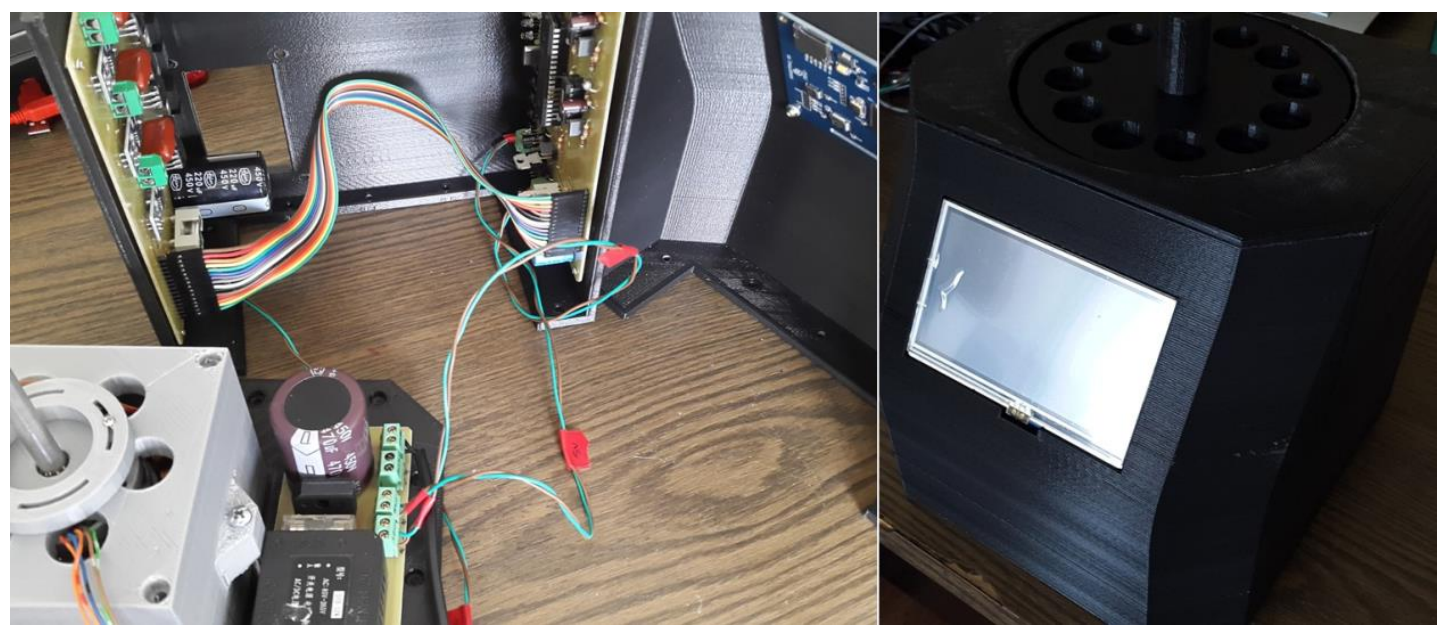

Şekil 8. Prototip santrifüj sistemine ait görüntüler (Pictures of the prototype centrifuge system)

Prototip medikal santrifüj sisteminin tahrik motoru olan ARM'nin sürücü ünitesinde anahtarlama elemanı olarak IGBT (Insulated Gate Bipolar Transistor) ve güç devre yapısı olarak da asimetrik köprü devresi kullanılmıştır. Özellikle düşük hızlarda akım değerini ölçebilmek ve dolayısıyla da akımı kontrol edebilmek adına sürücü ünitesinde akım sensörlerine de yer verilmiştir. Bunun yanında rotor konumu, alan etkili sensörlerin kullanıldığı bir sensör kartı vasıtasıyla algılanmaktadır. Motora ait faz gerilimi ve akımının dalga şeklini gösteren osiloskop ekranı görüntüsü Şekil 9'da gösterilmiştir. 


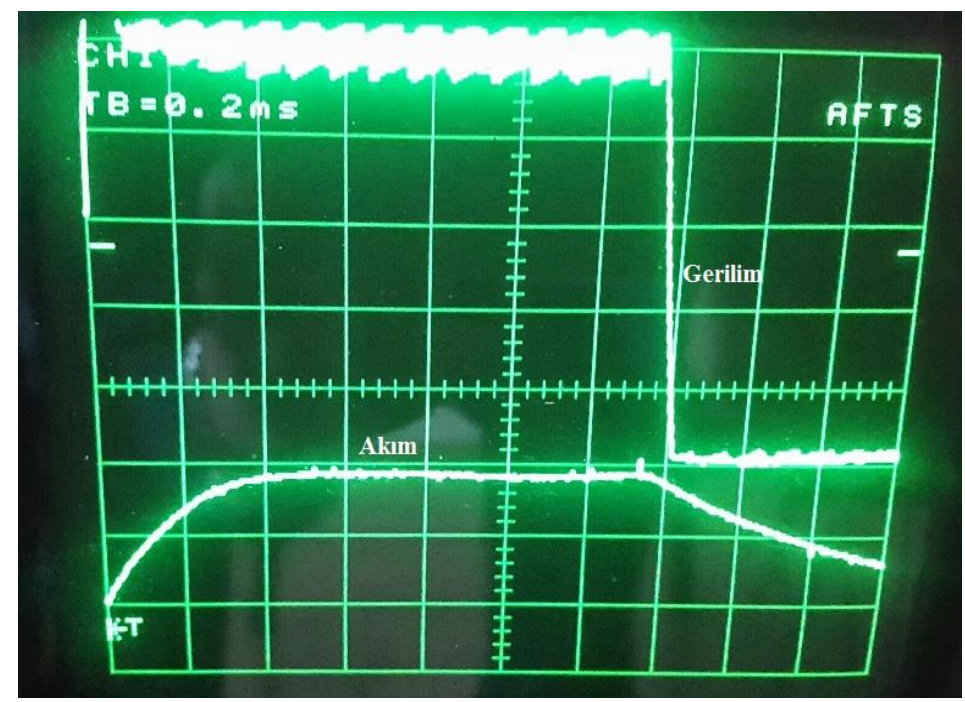

Şekil 9. ARM'nin faz gerilimi ve akımına ait osiloskop ekranı görüntüsü (Oscilloscope appearance of phase voltage and current waveforms of the SRM)

Daha önce değinildiği üzere, santrifüj sisteminin kontrolü tamamen dokunmatik ekran aracılığıyla sağlanmaktadır. Dokunmatik ekran için ITEAD Firması tarafından geliştirilen ve hızlı bir şekilde niteliği yüksek kullanıcı ara yüzleri oluşturmaya olanak sağlayan 4.3" ebadında bir ekran seçilmiştir. Şekil 10'da gösterildiği üzere prorotip cihazda şu an için basit anlamda en temel bir santrifüj cihazının işlevleri amaçlandığından, kullanıcının cihazın çalışma süresi ile devir hızını ayarlaması ve anlık olarak da bu değerleri takip etmesi sağlanmıştır. Bununla birlikte istenildiği taktirde gerek sürücü ünitesi gerekse de dokunmatik ekrana ait yazılımların revize edilmesi suretiyle çok daha farklı verilerin takip ve kontrol edilmesi mümkün olabilecektir.

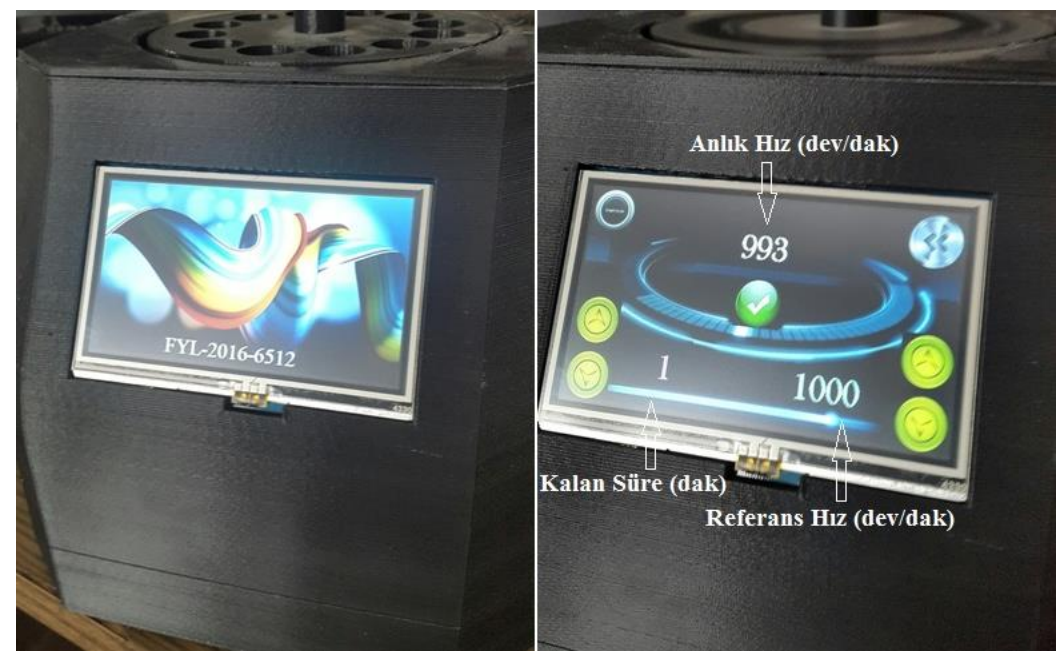

Şekil 10. Prototip santrifüj sisteminin test sürecinden alınmış görüntüler (Pictures of the prototype centrifuge system during the test)

\section{SONUÇ (CONCLUSION)}

Sunulan bu çalışmada, tahrik motoru olarak ARM'leri temel alan bir santrifüj sistemi tasarlanmış ve deneysel çalışmalar yapılmak üzere prototip olarak gerçekleştirilmiştir. Yapılan çalışma, diğer elektrik motorları ile kıyaslandığında üretim açısından maliyet başta gelmek üzere birçok avantaja sahip olan ARM'lerin tahrik motoru olarak kullanıldığg, teknolojik anlamda yenilikçi bir medikal santrifüj 
uygulaması olarak sunulmuştur. Geniş bir hız aralığı içerisinde çalıştırılmak üzere tasarlanan sistem, basit bir kullanıcı ara yüzü ile kullanıcılar için kolaylıklar sunmaktadır. Sonuç olarak yapılan çalışma, tıbbi açıdan vazgeçilmez cihazların başında gelen medikal santrifüj cihazlarının, farklı alternatiflerinin uygun maliyet ve teknolojik özelliklerle birlikte ortaya konulabileceğini göstermesi açısından önem arz etmektedir.

\section{TEŞEKKÜR (ACKNOWLEDGMENTS)}

$\mathrm{Bu}$ çalışma, Erciyes Üniversitesi Bilimsel Araştırma Projeleri Koordinasyon Birimi tarafindan FYL-2016-6512 kodu ile desteklenmiştir.

\section{KAYNAKLAR (REFERENCES)}

[1] M. Altınışık, Organik Kimya ve Biyokimya Uygulamaları, Adnan Menderes Üniversitesi, Aydın, Türkiye, 2007.

[2] P. J. Lawrenson, J. M. Stephenson, P. T. Blenkinsop, J. Corda, N. N. Fulton, Variable speed reluctance motors, Proc. IEE, 253-265, 1980.

[3] T. J. E. Miller, Switched reluctance motors and their control, Oxford University Press, Oxford, İngiltere, 1993.

[4] A. V. Radun, Design considerations for the switched reluctance motor, IEEE Transactions on Industry Applications 31:5, 1079-1087, 1995.

[5] R. Krishnan, Switched Reluctance Motor Drives Modeling, Simulation, Analysis, Design and Applications, CRC Press, New York, A.B.D., 2001.

[6] J. Poidl, W. Steiger, Variable speed drives and cenrifuges for zone 1 hazardous areas, Petroleum and Chemical Industry Conference Europe - Electrical and Instrumentation Applications (PCIC), 2008.

[7] F. Jiancheng, L. Xiquan, B. Han, K. Wang, Analysis of circulating current loss for high-speed permanent magnet motor, IEEE Transactions on Magnetics, 51:1, 2015.

[8] H. M. Yang, J. W. Cha, B. H. Baik, B. I. Kwon, Design and analysis of high speed BLDC motor for centrifuge, 18th International Conference on Electrical Machines and Systems (ICEMS), 2015.

[9] J. Pramudijanto, A. Ashfahani, A. Fatoni, S. A. Nugroho, PLC-based PID-predictive controller design for 3-phase induction motor on centrifugal machines for sugar manufacturing process, International Conference on Advanced Mechatronics, Intelligent Manufacture and Industrial Automation (ICAMIMIA), 2015.

[10] https://www.beckman.com/centrifuges 